\title{
Intermetallic Phase Evolution of Cold-Sprayed Ni-Ti Composite Coatings: Influence of As-Sprayed Chemical Composition
}

\author{
R. Nikbakht ${ }^{1} \cdot$ H. Assadi ${ }^{2} \cdot$ B. Jodoin ${ }^{1}$
}

Submitted: 17 August 2020/in revised form: 20 September 2020/Accepted: 10 October 2020/Published online: 8 November 2020 (C) ASM International 2020

\begin{abstract}
Owing to low-temperature deposition conditions and high deposition rate, cold spray offers unique advantages in manufacturing a wide variety of metallic and composite coatings including metal matrix composites produced from physically blended powders. One of the challenges of producing composite coatings using cold spray is the deviation of coatings composition from the blended feedstock powder composition. This is of utmost importance as it affects the composition and phase evolution of intermetallic forming coatings during post spray heat treatment. In this work, cold spray of composite $\mathrm{Ni}-\mathrm{Ti}$ coatings and formation of intermetallics from post spray heat treatment were investigated as a first step to examine the potential of producing equiatomic bulk Ni-Ti by cold spray. Three different physically blended $\mathrm{Ni}$ and $\mathrm{Ti}$ powders mixtures were sprayed on titanium substrates to address the coating composition variation from the blended feedstock powder and study its influence on phase evolution during post spray heat treatment. High-density and well-dispersed composite coatings were achieved for each case. EDS analysis revealed as-sprayed coatings with
\end{abstract}

This article is an invited paper selected from abstracts submittedfor the 2020 International Thermal Spray Conference, ITSC2020, that was to be held from June10-12, 2020, in Vienna, Austria. The conference was cancelled due to the coronavirus (COVID-19) pandemic. The paper has been expanded from the planned presentation.

\section{R. Nikbakh}

Jennifer.kelly@asminternational.org

1 Cold Spray Laboratory, University of Ottawa, Ottawa, ON, Canada

2 Brunel University London, Brunel Centre for Advanced Solidification Technology (BCAST), Uxbridge, UK
10.5, 35.9 and 56.9 at.\% $\mathrm{Ni}$ (and with balanced Ti ratios) from the three powder mixtures. Annealing treatments were conducted at 400,500 and $900{ }^{\circ} \mathrm{C}$ for 1 and $2 \mathrm{~h}$ and comparative studies of the intermetallic compound formations were carried out. Microstructural investigation showed that all three equilibrium intermetallics phases of binary $\mathrm{Ni}-\mathrm{Ti}$ phase diagram $\left(\mathrm{Ni}_{3} \mathrm{Ti}, \mathrm{Ti}_{2} \mathrm{Ni}\right.$ and $\left.\mathrm{NiTi}\right)$ formed in the two Ni-rich composite coatings with NiTi phase being maximum in the coating with the closest composition to equiatomic ratio while only $\mathrm{Ti}_{2} \mathrm{Ni}$ phase formed in the Ti-rich coating after annealing. Thermal etching analysis of coatings showed that NiTi phase forms with a gradient microstructure from $\mathrm{Ti}$ splats boundary toward the center of splats, which is attributed to the grain refinement of CS samples at splat boundary and intermetallic nucleation mechanism.

Keywords cold spray - feedstock powder composition · gradient structure - intermetallic phase evolution - metal matrix composite coatings $\cdot \mathrm{Ni}-\mathrm{Ti}$

\section{Introduction}

Cold spray (CS) is a powder consolidation method in which micron-size particles are accelerated through the expansion of a pressurized inert gas and impact onto a substrate at high velocities $(300-1200 \mathrm{~m} / \mathrm{s})($ Ref 1-3). The accelerated particles deposit on a substrate or previously deposited particles at velocities around or beyond a material and particle size-dependent critical velocity $(\operatorname{Ref} 4,5)$. Particle deposition in CS relies on solid-state deformation as particles remain at temperatures well below their melting temperature during the whole process, from acceleration to deposition (Ref 1-3). 
Due to the solid-state deposition nature of the process and high deposition rates, CS shows notable advantages in fabricating a wide variety of multicomponent coatings with different melting points, including metal matrix composites (MMC) (Ref 6-10). In this method, either different powders are fed using dual feeding (Ref 11), or blended or mechanically alloyed powders are fed in a single stream, to produce dense MMC coatings (Ref 12-14). Fabrication of MMC coatings using CS is a relatively easier and more economical route compared to thermal spraying (Ref 6, 7, 9, 15). Mixtures with several physical properties including reactive materials (Ref 16,17 ) can be sprayed without concern about reactions or phase transformations during the CS process (Ref 7, 13, 14, 18). The composite mixture can be sprayed either in near-net shape (Ref 19) or easily machined to the desired shapes (Ref 6). In the case of intermetallic forming mixtures, post spray heat treatments (PSHT) are conducted to form intermetallic compounds (Ref 6).

NiTi alloys are widely used as protective coating materials of Ti alloys (Ref 20) and stainless steels, which suffer from poor wear resistance or cavitation erosion (Ref 21-23). CS, with its ability to build up coatings at relatively low temperatures on almost any metallic substrates, has been used to deposit Ni-Ti coatings (Ref 21-23). Few studies have looked at CS of pre-alloyed Ni-Ti powder or mechanically activated elemental powders. For instance, the feasibility of Ni-Ti coating production by CS has been shown by depositing milled Ni-Ti powder mixtures (Ref 21, 22) and blended Ni-Ti powders (Ref 24). The poor deformability of NiTi intermetallic has shown to be a challenge for spraying thick coatings from pre-alloyed powders. As a result, the production of thick and wellbonded $\mathrm{Ni}$-Ti coatings has been considered more viable using blended Ni-Ti powder deposition instead of $\mathrm{NiTi}$ alloyed powders (Ref 21, 24, 25).

CS studies of multicomponent (blended) powders such as Ni-Ti (Ref 24), Ti-Al (Ref 26), Al-Ni (Ref 27, 28) and $\mathrm{Fe}-\mathrm{Al}$ (Ref 29) and subsequent heat treatments of coatings to produce intermetallics have been reported and comprehensively reviewed (Ref 6, 30, 31). Generally, the intermetallic evolution of CS MMCs presents two important challenges: i) final intermetallic products of as-sprayed dense CS samples are porous after PSHT, ii) the ultimate phase combination of MMCs after PSHT is usually multiphase (Ref 6), with phase evolution mechanisms potentially different from anticipated results based on diffusion couple experiments.

The formation of porosities was attributed to diffusion differences of elements in Ni-Ti (Ref 24) and Ti-Al (Ref 26) and Kirkendall effect. The intermetallic evolution of $\mathrm{Ni}-\mathrm{Ti}$ pair showed that the quality of bonding also influences the amount of interfacial porosities and discontinuities developed during PSHT in addition to the Kirkendall effect (Ref 32).

In CS of MMCs, the as-sprayed coating composition may significantly deviate from that of the blended feedstock powders. This deviation stems from the fact that each powder material experiences its specific deposition efficiency (DE), which might be significantly different for each material. Furthermore, this specific DE is also influenced by the interactions between materials, resulting in a specific DE hard to predict (Ref 9). It has been shown that $\mathrm{CS}$ of $\mathrm{Ti}$ and $\mathrm{Ni}$ on dissimilar substrate material results in different critical velocities and deposition characteristics compared to similar $\mathrm{Ti} / \mathrm{Ti}$ and $\mathrm{Ni} / \mathrm{Ni}$ powder/substrate combinations (Ref 32-35). To overcome the coating composition deviation in CS, the feedstock powder is usually tailored based on experimental trial and errors to reach the final composition of interest. This change of feedstock powder composition also influences the deformation and bonding of particles. For instance, an increase of highdensity element in a powder mixture increases the tamping effect-which in turn may influence intermetallic phase evolution during PSHT by changing the coating composition and bonding quality (cohesion of coating) (Ref 36). Moreover, microstructural characteristics of CS coatings such as severe plastic deformation (Ref 37$)$, and possibility of amorphous phase formation and intermixing (Ref 32, 38-40) might enhance elemental diffusion rate. It has been shown that change of diffusion rate influences the kinetics of phase evolution and consequently final phase combination (Ref 41).

Owing to unique properties including shape memory and superelastic properties, NiTi phase is of utmost importance in the binary Ni-Ti system (Ref (Ref 42). In this work, as a primary step to have a look at the capability of manufacturing either bulk NiTi or NiTi coatings via CS, composite Ni-Ti coatings were produced using blended $\mathrm{Ni}$ and $\mathrm{Ti}$ powders with three different feedstock powder composition and formation of intermetallics during PSHT were investigated with the different heat treatment procedure. Ni-Ti composite coatings were sprayed using one Ti powder and two different Ni powders with different particle sizes. The effect of feedstock powder composition on coatings characteristics (microstructure and composition) was studied using scanning electron microscopy and x-ray energy-dispersive spectroscopy (EDS). The influence of chemical composition and level of cold deformation of assprayed coatings on microstructure and phase evolution of $\mathrm{Ni}$-Ti intermetallics during PSHT at $400{ }^{\circ} \mathrm{C}$ and $500{ }^{\circ} \mathrm{C}$ and $900{ }^{\circ} \mathrm{C}$ were performed. Thermal etching of annealed samples was used to study intermetallic formation mechanisms after PSHT at $900{ }^{\circ} \mathrm{C}$. 


\section{Experimental Procedure}

Two spherical gas atomized Ni powders (CP-Ni, Atlantic Equipment Engineers, Upper Saddle River, NJ, USA) with two different particle size distribution (referred to as Ni-1 and $\mathrm{Ni}-2$ ) and a spherical plasma atomized Ti powder (CPTi, Advanced Powder and Coatings, Boisbriand, Canada) were used as feedstock materials.

CS coatings were produced using the commercially available EP Series SST Cold Spray System (Centerline (Windsor) Ltd., Windsor, Ontario, Canada). A stainless steel de Laval nozzle with a throat diameter, diverging section and exit diameter of, respectively, $2 \mathrm{~mm}, 120 \mathrm{~mm}$ and $6.6 \mathrm{~mm}$ was used. Powders were sprayed using nitrogen as the propellant gas. The powder size distribution was measured by laser diffraction analysis (Microtrac model S3500, Montgomeryville, PA, USA), with powder dispersed in a standard solution. Physically blended $\mathrm{Ni}$ and $\mathrm{Ti}$ powder mixtures with equivalent atomic, volume and optimized ratios (calculated based on DE of $\mathrm{Ni}$ and $\mathrm{Ti}$ to reach coating composition as close as possible to equiatomic ratio) with $50,61.7$ and $75.4 \%$ at. $\mathrm{Ni}$ (balanced $\mathrm{Ti}$ ) ratios. The blended powders were sprayed on titanium substrates. $C_{\mathrm{a}}, C_{\mathrm{v}}$ and $C_{\mathrm{o}}$ symbols are, respectively, used for the coatings sprayed using equivalent atomic, equivalent volume and optimized ratios of Ni-Ti blends. The spraying parameters and feedstock powder compositions used in the current work are listed in Table 1.

PSHT of samples was done at 400,500 and $900{ }^{\circ} \mathrm{C}$ for 2 , 2 and $1 \mathrm{~h}$, respectively, in a vacuum furnace with vacuum level below $10^{-6}$ torr. The microstructure and phase combination of as-sprayed and heat-treated coatings were examined using a scanning electron microscope (SEM) (EVO MA-10, Carl Zeiss AG, Oberkochen, Germany) equipped with secondary (SE) and backscattering electron (BSE) detectors as well as EDS.

\section{Results and Discussion}

\section{Powder Morphology}

The morphology of Ni-1, Ni-2 and Ti feedstock powders is shown in Fig. 1 (a-c). SEM observations of the free-standing particles reveal a spherical morphology for all three powders with some satellites present. The powder size distribution analysis showed that a mean particle size of $6.63 \mu \mathrm{m}, 24.53 \mu \mathrm{m}$ and $30.66 \mu \mathrm{m}$ for $\mathrm{Ni}-1, \mathrm{Ni}-2$ and $\mathrm{Ti}$ powders, respectively (Fig. $1 \mathrm{~d}$ ). Powder particle distribution shows that $\mathrm{Ni}-2$ and $\mathrm{Ti}$ powder have a relatively narrow particle size distribution while $\mathrm{Ni}-1$ powder is significantly finer with a narrow particle size distribution.

\section{As-Sprayed Ni-Ti Composite Coatings}

SEM cross-section images of composite coatings produced using the three different blended $\mathrm{Ni}$-Ti powder mixtures are presented in Fig. 2(a1-c1), with $\mathrm{Ti}$ and $\mathrm{Ni}$ particles in gray and white contrast respectively. Both $\mathrm{Ni}$ and $\mathrm{Ti}$ particles are homogeneously distributed in the composite coatings. The coatings sprayed with $\mathrm{C}_{\mathrm{a}}$ and $\mathrm{C}_{\mathrm{v}}$ powder mixtures have some porosities (less than $1 \%$ ) while the coatings sprayed with $\mathrm{C}_{\mathrm{o}}$ powder mixture are fully dense. The higher magnification images in Fig. 2(a2-c2) indicate that increasing the $\mathrm{Ni}$ content and particle size of the blended feedstock powders increases the deformation level of both $\mathrm{Ni}$ and Ti particles in the coatings, with Ti particles exhibiting a larger flattening ratio than usually observed in CS of single component Ti coatings (Ref 32). These increased deformation levels are attributed to the tamping (shot peening) effect of the Ni particles, which have lower DEs compared to Ti particles as a smaller fraction of the initial powder composition is retained compared to $\mathrm{Ti}$ ( Ref 32).

Additionally, very thin layers of $\mathrm{Ni}$ (lines) with a thickness of $1 \mu \mathrm{m}$ or less (with brighter contrast) are observed between Ti splats of Fig. 2(a2-c2). They do not seem to be caused by the tamping/flattening of deposited

Table 1 Spraying parameters and feedstock powders compositions

\begin{tabular}{|c|c|c|c|c|c|c|c|}
\hline Composite coatings & Powders & $\begin{array}{c}\text { Composition } \\
\text { (Ni\% at.) }\end{array}$ & $\begin{array}{c}\text { Temperature } \\
\left({ }^{\circ} \mathrm{C}\right)\end{array}$ & $\begin{array}{l}\text { Pressure } \\
(\mathrm{MPa})\end{array}$ & $\begin{array}{c}\text { Stand of } \\
\text { Distance }(\mathrm{mm})\end{array}$ & $\begin{array}{c}\text { Traverse } \\
\text { speed }(\mathrm{mm})\end{array}$ & $\begin{array}{c}\text { Feedstock } \\
\text { powder }(\mathrm{g} / \mathrm{m})\end{array}$ \\
\hline $\mathrm{C}_{\mathrm{a}}$ & $\mathrm{Ni}-1, \mathrm{Ti}$ & 50 & 350 & 3.4 & 15 & 5 & 7.2 \\
\hline $\mathrm{C}_{\mathrm{v}}$ & $\mathrm{Ni}-2, \mathrm{Ti}$ & 61.7 & 300 & 3.4 & 15 & 5 & 7.2 \\
\hline $\mathrm{C}_{\mathrm{o}}$ & $\mathrm{Ni}-2, \mathrm{Ti}$ & 75.4 & 300 & 3.4 & 15 & 5 & 6.5 \\
\hline
\end{tabular}


Fig. 1 SEM micrograph of (a) spherical Ni-1 powder, (b) spherical Ni-2 powder, (c) spherical Ti powder and (d) measured particle size distribution of feedstock powders
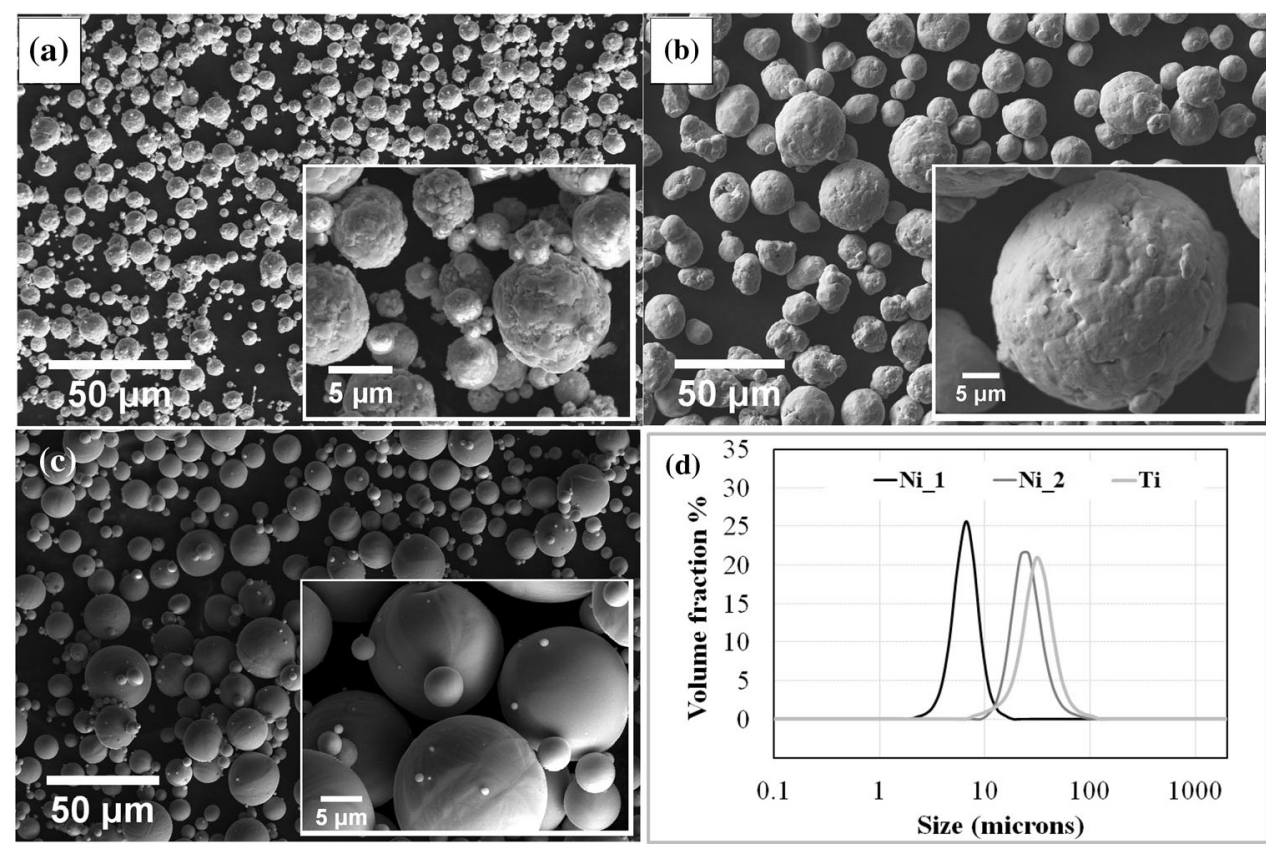
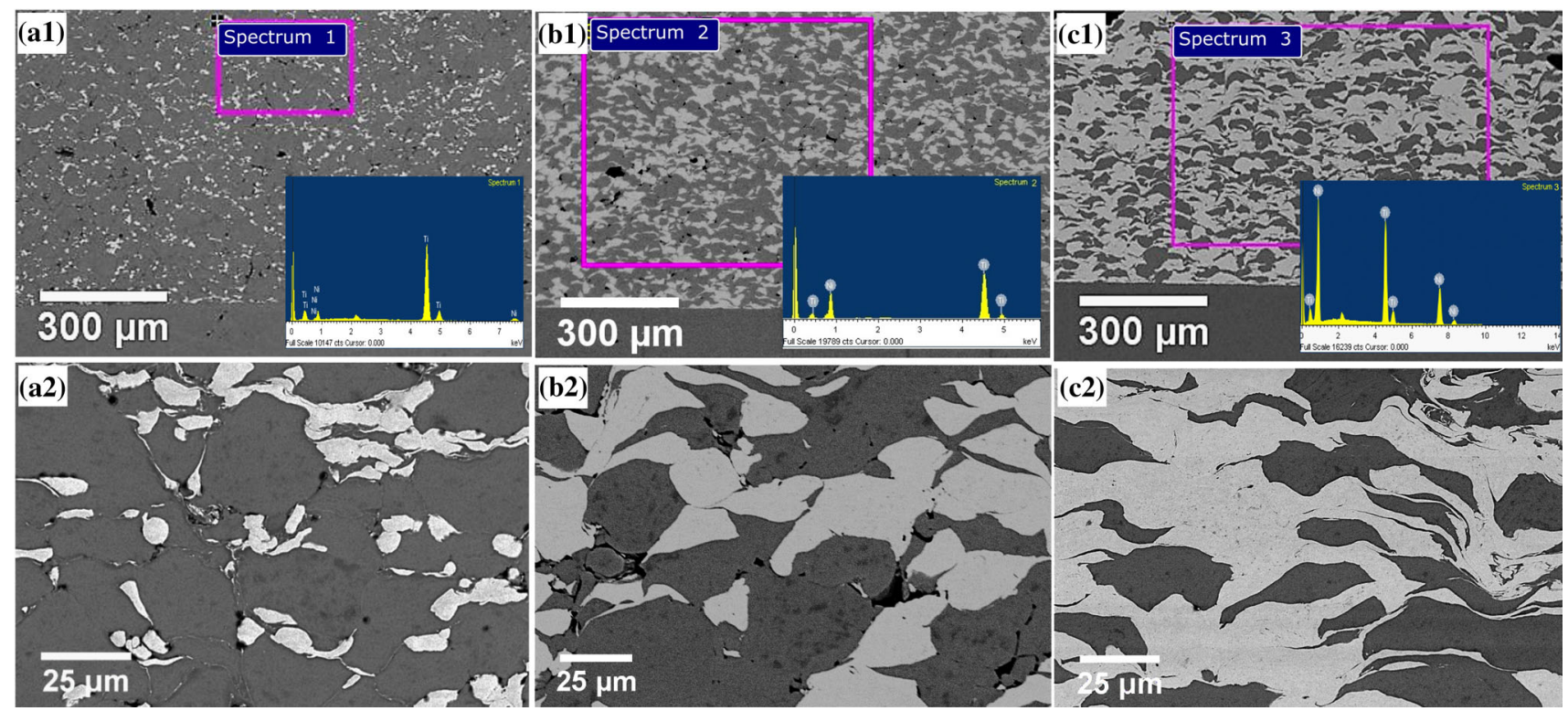

Fig. 2 SEM image of Ni-Ti composite coating sprayed using three different blended Ni-Ti powder composition. (a1), (b1) and (c1), respectively, sprayed using equiatomic, equivolume and optimized ratio. (a2)-(c2), respectively, shows (a)-(c) in higher magnifications

Ni particles, but are most likely remnant of impacted particles that did not succeed to deposit (Ref 43). It is expected that the $C_{\mathrm{o}}$ coating, exhibiting more particle deformation would display better cohesion than $C_{\mathrm{a}}$ and $C_{\mathrm{v}}$ coatings.

The coatings composition is evaluated using EDS surface analysis (selected areas used are shown in Fig. 2(a1)(c1)) and is presented in Fig. 3. Comparison of $\mathrm{Ni}$ at.\% in blended powders and composite coatings shows that the coatings composition deviates from the feedstock blended powders composition, with lower Ni levels retained in the coatings compared to the feedstock powder. $C_{\mathrm{a}}$ and $C_{\mathrm{v}}$ coatings have a Ti-rich composition while $C_{\mathrm{o}}$ coating has a composition closer to equiatomic NiTi composition. $\mathrm{C}_{\mathrm{a}}$ has the highest deviation from feedstock powder composition, which is attributed to the fact that fine Ni-1 and Ti powders have significant DE differences. The increase of Ni size and content in the blended powder in $C_{\mathrm{v}}$ and $C_{\mathrm{o}}$ result in a significant increase in $\mathrm{Ni}$ content of the coating, as $\mathrm{Ni}-2$ powder has a higher DE compared to Ni-1 (Ref 32). It is interesting to note that for the spray parameters used in the 
Fig. 3 Composition of Ni-Ti blended powders and composite coating sprayed using three different blended Ni-Ti powder composition

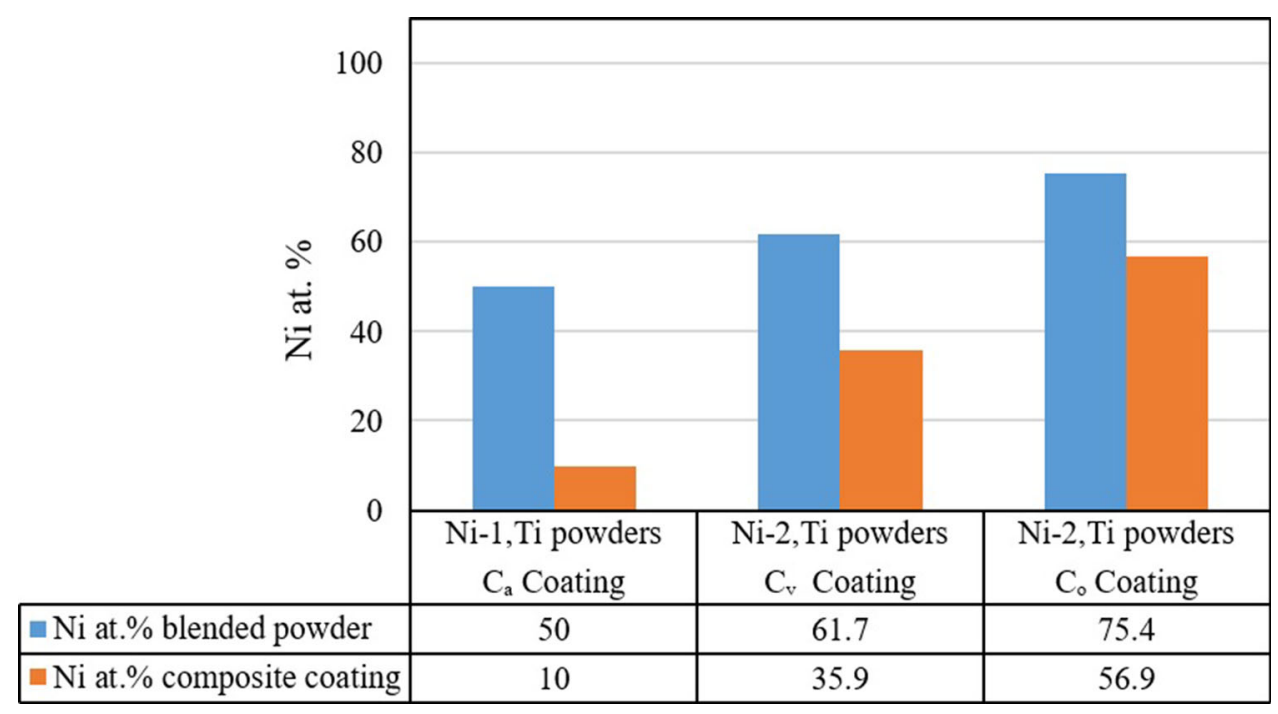

current work, both $\mathrm{Ni}-1$ and $\mathrm{Ni}-2$ failed to deposit or exhibited very low DE (less than 1\%) and Ti produced porous coatings when these powders were sprayed separately, while both $\mathrm{Ni}$ and $\mathrm{Ti}$ successfully deposited when sprayed in mixtures. In the latter case, coatings had lower porosity level compared to the pure Ti case, demonstrating the importance of material interactions. The latter explains coating composition deviation from feedstock powder composition, in addition to DE differences of the components in composite coatings: the deposition behavior of mixed powders is not the average of individual components.

\section{Microstructure Evolution after Heat Treatment}

In addition to composition deviation from that of feedstock powder, the stored energy and lattice imperfections in the coatings as a result of cold deformation in CS might alter the phase evolution mechanism, microstructure and kinetics in CS intermetallic forming systems compared to those of common powder metallurgy. During PSHT of CS samples, two phenomena occur simultaneously: (i) the cold deformed microstructure recovers or recrystallizes during annealing, and (ii) new phases nucleate and grow. To analyze the microstructure evolution and grain refinement of CS composite Ni-Ti samples during annealing, $\mathrm{C}_{\mathrm{o}}$ coatings were heat treated at $400^{\circ} \mathrm{C}$ and $500^{\circ} \mathrm{C}$ for $2 \mathrm{~h}$. The microstructure of annealed samples is presented in Fig. 4. Figure 4(a), shows $\mathrm{Ni}$ and $\mathrm{Ti}$ splats of $C_{\mathrm{o}}$ coatings at high magnification. The microstructure and different grain orientation of splats appeared as a result of electron channelling effect. Electron channelling works based on the fact that the backscattered electron intensity is strongly dependent on the orientation of the crystal lattice planes with respect to the incident electron beam (Ref 44).
Therefore, the average gray level is constant inside individual grains and represents backscattering intensity. The channelling contrast was observed between the equiaxed grains of splat boundaries.

From Fig. 4(a) and the higher magnification image of the selected area of Fig. 4(a), shown in 4(b), one can see that $\mathrm{Ni}$ splats have a bimodal microstructure with fine equiaxed submicron grains (in the range $500 \mathrm{~nm}$ ) in some areas of splat boundaries and larger micron-size grains (in the range of 5 microns) at the interior of the splats. The fine grains at splat boundaries are either dynamically recrystallized grains that were formed during high strain rate deformation and grew to some extent during the annealing treatment or statically recrystallized grains that have nucleated and grown from deformed grains. Similarly, grain refinement is expected to take place at $\mathrm{Ti}$ splat boundaries as reported in the literature for $\mathrm{Ti}$ and other materials (Ref 45, 46).

No intermetallic phase was distinguishable at splat boundaries of Fig. 4(a) and (b) at the resolution used. Figure $4(\mathrm{c})$ shows that after the heat treatment at $500^{\circ} \mathrm{C}$, fine intermetallics formed at $\mathrm{Ni} / \mathrm{Ti}$ interface (marked with dotted lines in Fig. 4(c)) and it is hypothesized that they grow toward the $\mathrm{Ti}$ splat. This implies that $\mathrm{Ni}$ is the dominant diffuser, in accordance with the literature on interdiffusion of Ni-Ti system (Ref 47). A close look at Ni/ Ti splat interfaces shows that thin intermetallics did not form continuously at the whole interface area and that they all present various thicknesses, suggesting a role of localized deformation and bonding in the kinetics of intermetallic phase nucleation at $\mathrm{Ni} / \mathrm{Ti}$ interface (Ref 33). Similarly to what was observed for the annealing temperature of $400^{\circ} \mathrm{C}, \mathrm{Ni}$ splats exhibit very fine grains at the splat boundaries. Regardless of the origin of these recrystallized grains at splat boundaries, they accelerate the 

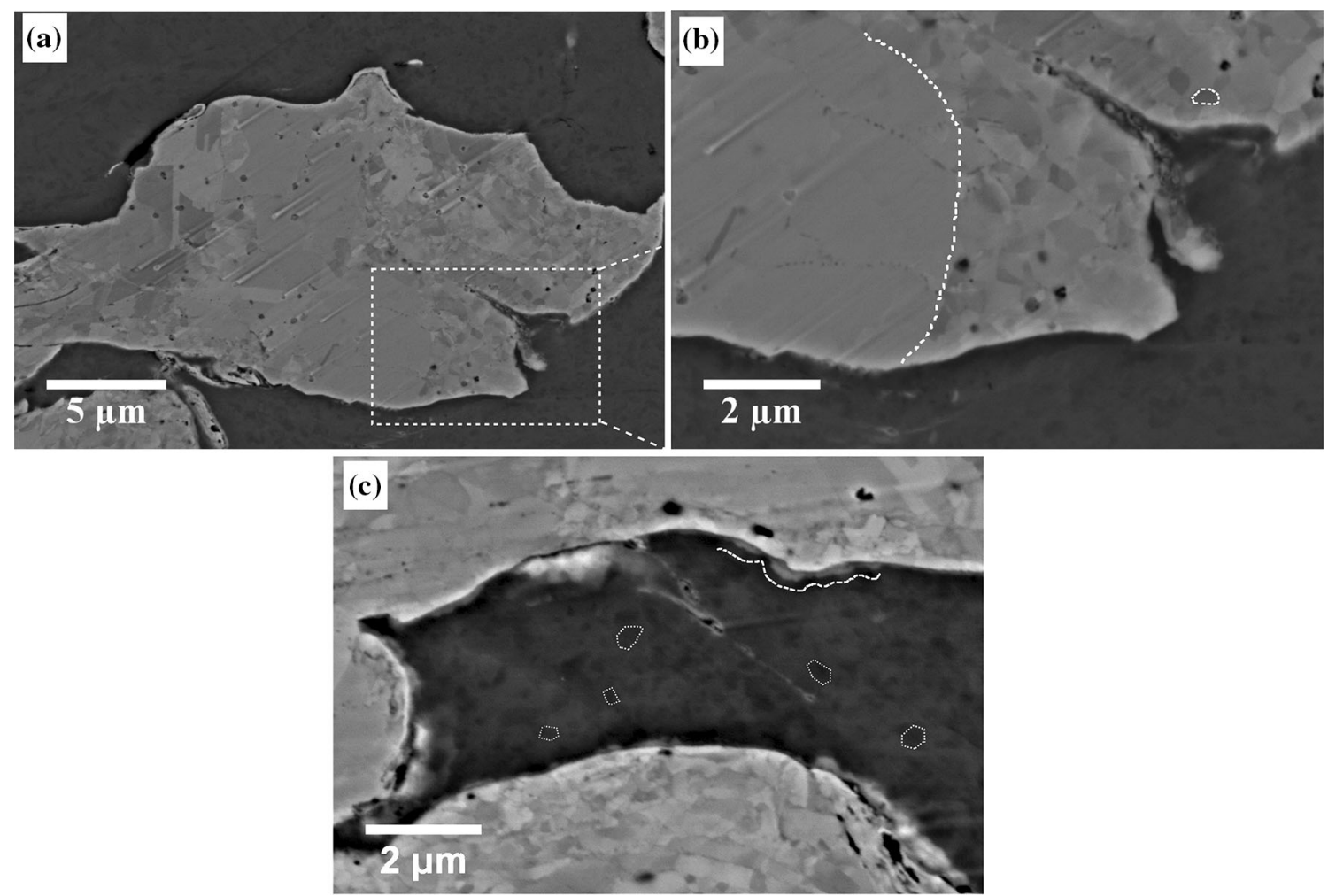

Fig. 4 SEM image of Ni-Ti composite after heat treatment. (a) and (b) annealed at $400^{\circ} \mathrm{C}$ for $2 \mathrm{~h}$, (c) annealed at $500^{\circ} \mathrm{C}$ for $2 \mathrm{~h}$

diffusion rate by grain boundary diffusion, in particular at low annealing temperatures (Ref 48).

In order to investigate the intermetallic phase evolution, PSHT has been performed at $900{ }^{\circ} \mathrm{C}$ on the composite coatings. Figure 5 shows the cross section of the $C_{\mathrm{a}}, C_{\mathrm{v}}$ and $\mathrm{C}_{\mathrm{o}}$ coatings after $1 \mathrm{~h}$ annealing treatment at $900^{\circ} \mathrm{C}$. Figure 5(a) and EDS analysis of the microstructure show that the $\mathrm{Ni}$ phase of $\mathrm{C}_{\mathrm{a}}$ coating was completely consumed and the $\alpha \mathrm{Ti}$ phase transformed to $\beta \mathrm{Ti}(\mathrm{Ni})$ solid solution at high temperature. During cooling, this high-temperature $\beta \mathrm{Ti}(\mathrm{Ni})$ phase transformed into eutectoid $\mathrm{Ti}_{2} \mathrm{Ni}$ and $\alpha \mathrm{Ti}$ products. $\mathrm{Ti}_{2} \mathrm{Ni}$ is the only intermetallic that exists in the microstructure after the annealing treatment of $\mathrm{C}_{\mathrm{a}}$ coating. SEM image of annealed microstructure of $\mathrm{C}_{\mathrm{v}}$ coatings (Fig. 5(b)) shows that with an increase of Ni content in the as-sprayed coating, all three equilibrium intermetallic phases of $\mathrm{Ni}-\mathrm{Ti}$ binary system $\left(\mathrm{Ti}_{2} \mathrm{Ni}, \mathrm{NiTi}\right.$ and $\left.\mathrm{Ni}_{3} \mathrm{Ti}\right)$ coexist in the microstructure with some unreacted $\mathrm{Ti}$. In the Ni-rich composite coating $\mathrm{C}_{\mathrm{o}}$ (Fig. 5 (c)), all three intermetallics coexist with traces of $\mathrm{Ti}$ and some unreacted $\mathrm{Ni}$ which is hardly distinguishable from $\mathrm{Ni}_{3} \mathrm{Ti}$ phase.

Some porosities formed during heat treatment of coatings mostly inside the Ni splats and splat boundaries, with $C_{\mathrm{v}}$ coating having the highest amount of porosities. Considering the inherent diffusion differences of $\mathrm{Ni}$ and $\mathrm{Ti}$ elements, formation of porosities in the $\mathrm{Ni}$ phase is attributed to Kirkendall effect. The porosities formed at splat boundaries of $C_{\mathrm{v}}$ coating can be ascribed to the lesser particle deformation and potentially lower interparticle bonding quality in $C_{\mathrm{v}}$ coating compared to $C_{\mathrm{o}}$ coating in combination with Kirkendall effect. The finer particle size and lower amount of $\mathrm{Ni}$ phase in the $C_{\mathrm{a}}$ coating result in a decrease of diffusion distance of $\mathrm{Ti}$ (and an increase of diffusion distance of $\mathrm{Ni}$ ) and consequently increase of $\mathrm{Ti}$ diffusion, confirmed by the fact that $\mathrm{Ti}_{2} \mathrm{Ni}$ intermetallics formed on the original $\mathrm{Ni}$ splats. This is why fine $\mathrm{Ni}$ particles are used in powder metallurgy, to minimize the porosity formation in the synthesis of NiTi intermetallic from Ni and Ti powders (Ref 49).

The phase combination of coatings after heat treatment is shown in Fig. 6. They were calculated using ImageJ based on the contrast of the phases of the cross-section images. It shows that $\mathrm{C}_{\mathrm{o}}$ coating has the highest ratio of $\mathrm{NiTi}$ and $\mathrm{Ni}_{3} \mathrm{Ti}+\mathrm{Ni}$ phases and the least amount of $\mathrm{Ti}_{2} \mathrm{Ni}$ phase among all the coatings. It can be seen that the $\mathrm{C}_{\mathrm{v}}$ coating has more unreacted $\mathrm{Ti}$ phase, and $\mathrm{Ti}_{2} \mathrm{Ni}$ but less $\mathrm{NiTi}$ and $\mathrm{Ni}+\mathrm{Ni}_{3} \mathrm{Ti}$ compared to the $\mathrm{C}_{\mathrm{o}}$ coating, as expected. The composition of $\mathrm{C}_{\mathrm{a}}$ coatings is a combination of $\mathrm{Ti}$ and $\mathrm{Ti}_{2} \mathrm{Ni}$ phases and as expected $\mathrm{Ti}_{2} \mathrm{Ni}$ is the sole intermetallic phase at equilibrium.

Based on the results of Fig. 5 and 6, it is concluded that the feedstock powder composition has a decisive role in the phase composition of the coatings after PSHT. In the case of the Ni-Ti binary system, the NiTi phase is of utmost 

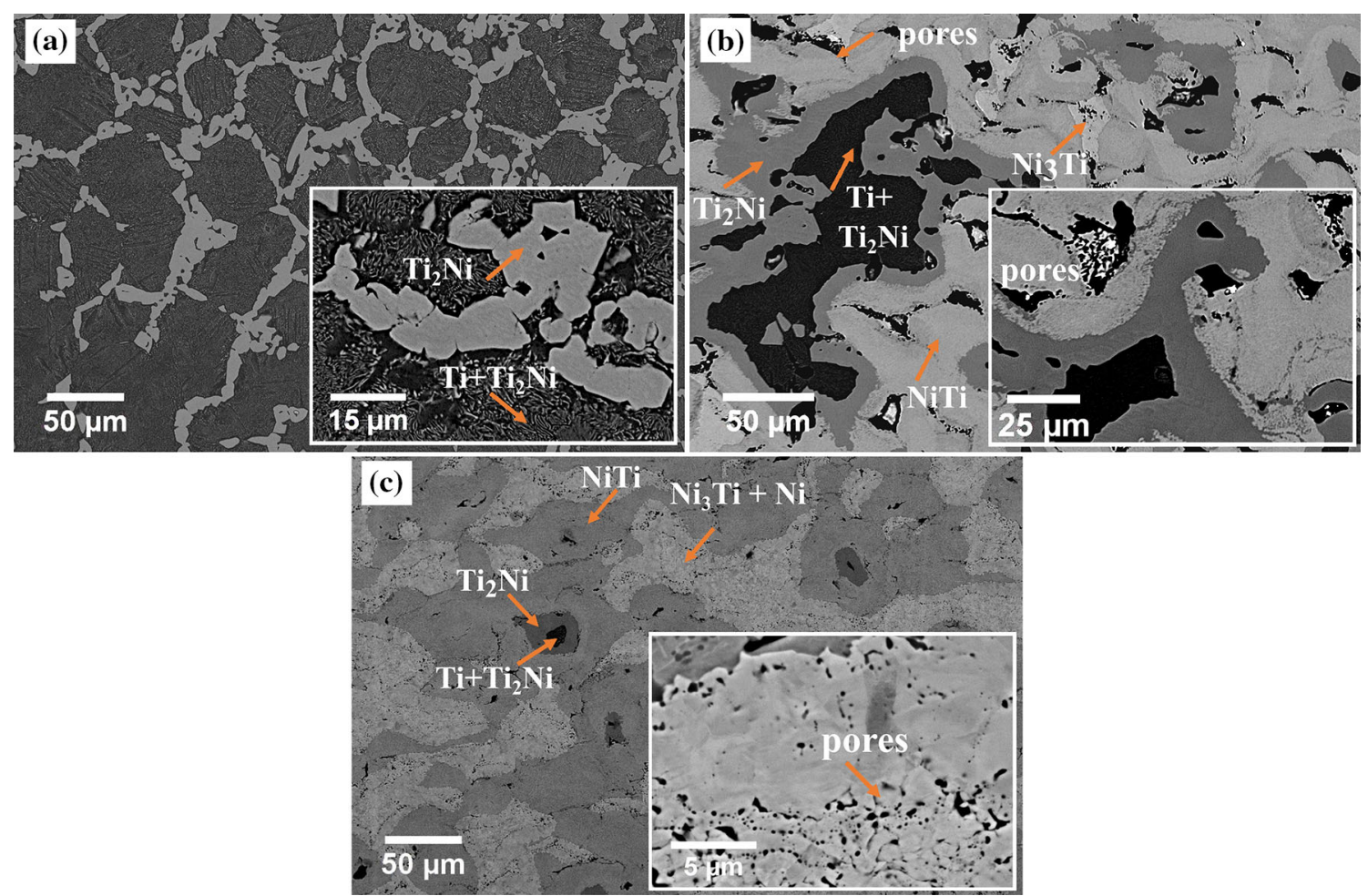

Fig. $5 \mathrm{SEM}$ image of annealed $\mathrm{Ni}-\mathrm{Ti}$ composite samples at $900^{\circ} \mathrm{C}$ for $1 \mathrm{~h}$. (a) Ca coating, (b) $\mathrm{Cv}$ coating and (c) Co coating

Fig. 6 Phase composition of annealed composite samples after heat treatment at $900^{\circ} \mathrm{C}$ for $1 \mathrm{~h}$

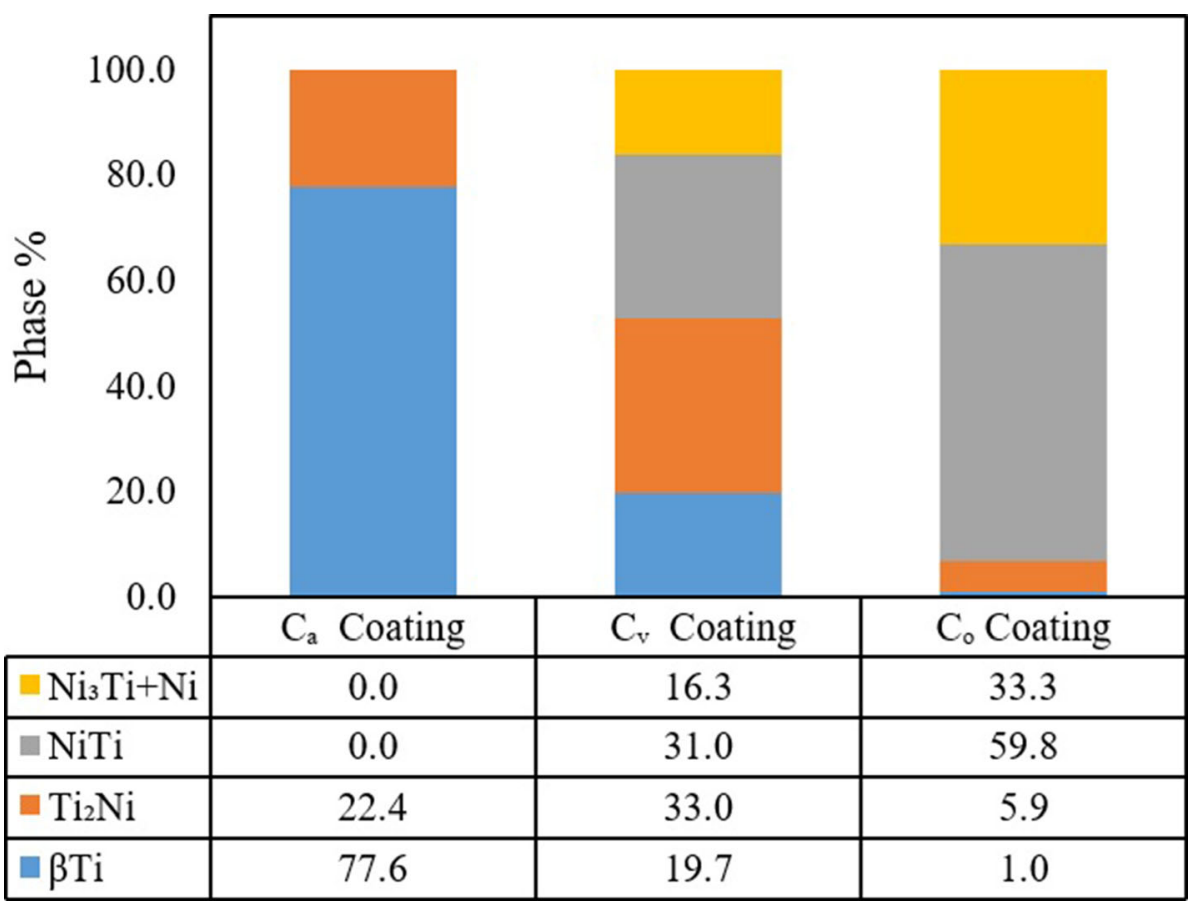

importance between three intermetallics of binary $\mathrm{Ni}-\mathrm{Ti}$ system for its potential use in commercial applications and has the highest fraction (around $60 \%$ ) in the $\mathrm{C}_{\mathrm{o}}$ coating. To further increase this NiTi content, the composition of the as-sprayed coating should be as close as possible to equiatomic Ni-Ti composition. Additionally, initial feedstock powder composition has an important effect on the density of as-sprayed $\mathrm{Ni}-\mathrm{Ti}$ coatings and formation of porosities during PSHT which clearly show the role of manufacturing characteristics of coatings on the final phase 
composition. Furthermore, results show that the heat treatment procedure also plays a significant role in the microstructure evolution and formation of porosities during PSHT of Ni-Ti composite coatings.

\section{Structure and Phase Evolution During Heat Treatment}

In order to further explore the intermetallic phase evolution, thermal etching was done at $900^{\circ} \mathrm{C}$ on the composite coatings. The as-sprayed samples were polished, then heat treatment was performed in a vacuum furnace. The $C_{\mathrm{o}}$ annealed sample (which contained the highest percentage of NiTi) was analyzed to investigate the diffusion and intermetallic formation mechanism using thermal etching (thermal grooving) (Ref 50, 51). In this method, grain boundaries at the material surface appear as a result of grooving or local sublimation of atoms of grain boundaries which have higher surface energy (Ref 50,51). Thermal grooves can develop in association with mobile as well as stationary grain boundaries. This is important because during the intermetallic phase evolution of CS composite samples, the microstructure is continuously changing as results of grain refinement (as it has been shown in Fig. 4), and nucleation and growth of new phases.

Figure 7(a) shows thermally etched grain grooves of Ni$\mathrm{Ti}$ Microstructure. Ti splat boundaries expanded upon annealing while Ni phase was shrunk (consumed). This indicates that $\mathrm{Ni}$ is the dominant diffusing element and diffuses toward the $\mathrm{Ti}$ splats and intermetallic phase(s) mostly formed on Ti splats. The higher magnification image in Fig. 7(b) shows that the porosities were formed on the Ni side close to Ni/Ti interfaces as a result of the Kirkendall effect. Figure 7(c) shows that Ti splats have a gradient grain structure varying from fine submicron grains, with grain size of about $500 \mathrm{~nm}$ at the Ti splat boundaries, to coarser micron-size grains in the range of 5 microns toward the splat center. Furthermore, this Figure in combination with the phase analysis of the cross-section image of $\mathrm{C}_{\mathrm{o}}$ coating (Fig. 5) confirms that after $1 \mathrm{~h}$ annealing at $900^{\circ} \mathrm{C}$, the original $\mathrm{Ti}$ splats of composite samples were mostly consumed and transformed to NiTi phase with a gradient microstructure.

Gradient and heterogeneous structures have lately attracted a lot of attention in materials engineering because they retain ductility while increasing the strength of materials. This is of utmost importance because these two
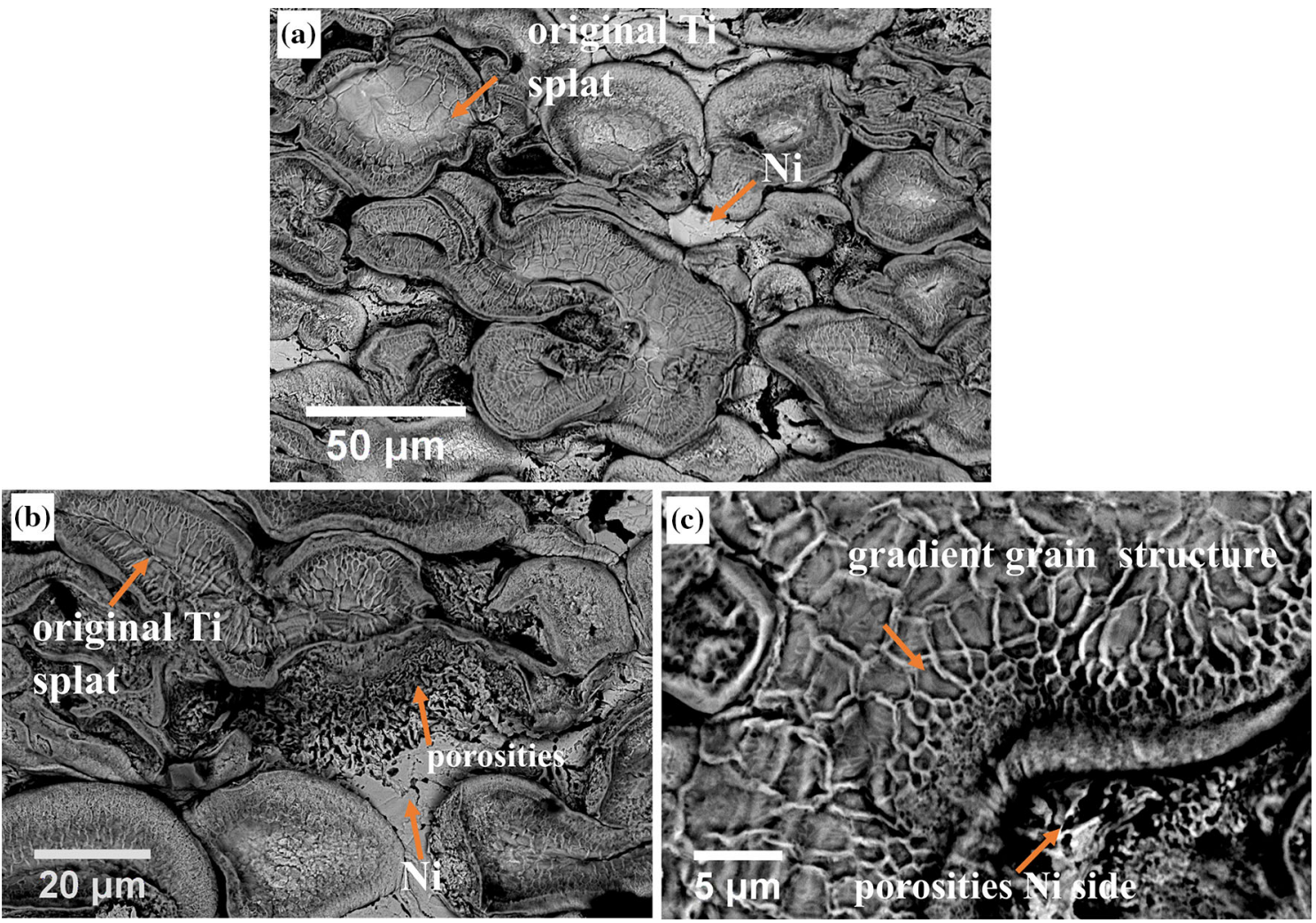

Fig. 7 SEM image of Co Ni-Ti composite coating after annealing treatment of $\mathrm{Ni}-\mathrm{Ti}$ mixture at three different magnifications from (a) to (c). Light gray shows unreacted $\mathrm{Ni}$ and dark gray shows initial splats of $\mathrm{Ti}$ which either completely or partially transformed into intermetallic phases. The dark color shows the porosities 
properties of materials are mutually exclusive (Ref 52). The formation of this gradient structure is attributed to both the microstructure evolution/recrystallization of cold deformed samples and intermetallic phase nucleation/growth mechanisms.

The schematic microstructure of as-sprayed $\mathrm{Ti}$ splat surrounded by Ni splats is drawn in Fig. 8(a) (and in higher magnification in Fig. 8(c)) based on EBSD analysis of this sample (not reported here) and microstructure analysis of CS Ti and Ni splats, confirmed also from the literature (Ref 53-55). The coating microstructure analysis showed that particle boundaries experience severe plastic deformation upon impact. As shown in Fig. 8(a) and (c), a fine equiaxed grain structure with high angle grain boundaries forms upon impact at $\mathrm{Ti}$ and $\mathrm{Ni}$ splat boundaries as a result of dynamic recrystallization (DRX) (region 2 in Fig. 8(c)). For Ni, the dynamically recrystallized grains were assumed to form mostly at highly strained sheared zones as reported in the literature and observed in Fig. 4. The dynamically recrystallized grains were considered to form all around the
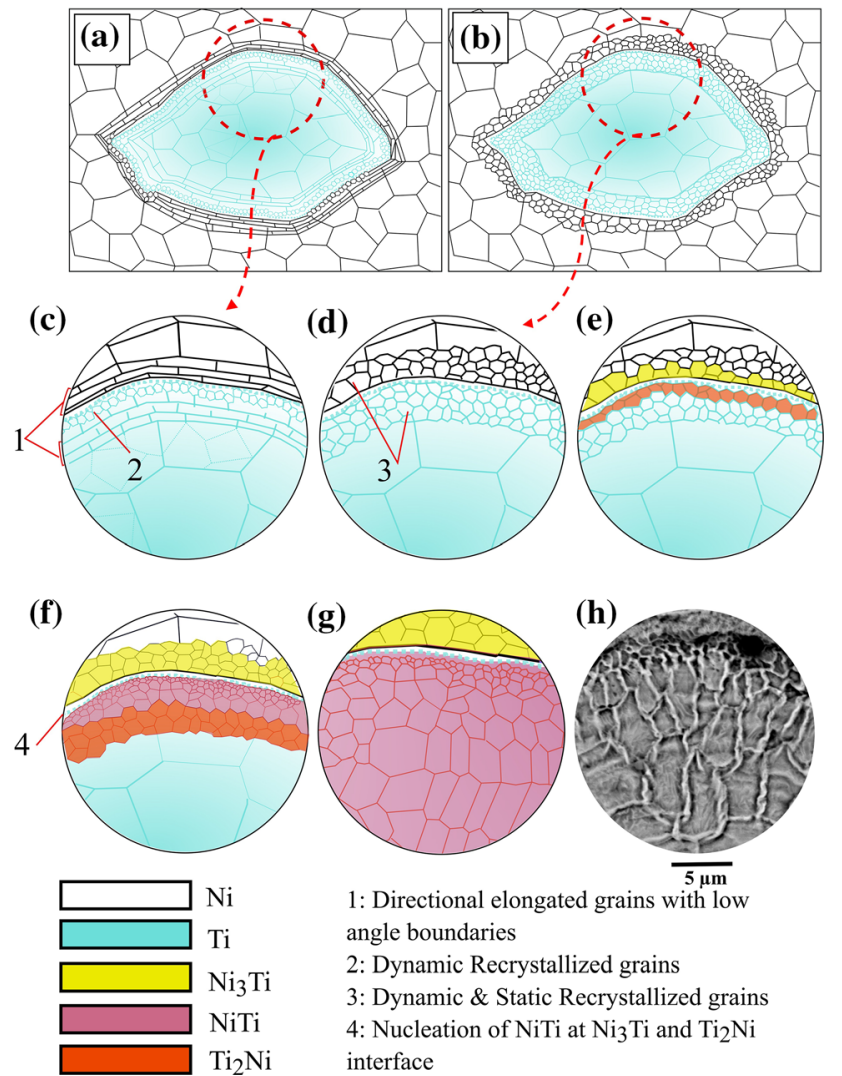

1: Directional elongated grains with low angle boundaries

2: Dynamic Recrystallized grains

3: Dynamic \& Static Recrystallized grains

4: Nucleation of $\mathrm{NiTi}$ at $\mathrm{Ni}_{3} \mathrm{Ti}$ and $\mathrm{Ti}_{2} \mathrm{Ni}$ interface

Fig. 8 Schematic of the gradient grain structure evolution of intermetallics during PSHT of CS Ni-Ti samples. (a) and (c) the schematic microstructure of as-sprayed sample, (b) and (d) after recrystallization during annealing, (e) early stage of intermetallic formation, (f) after nucleation of NiTi phase, (g) gradient microstructure of NiTi intermetallics after phase formation and (h) experimental gradient microstructure of NiTi intermetallics
Ti splat boundaries, which is supported by the fine submicron structure of Ti splat boundaries in Fig. 7.

Next to the equiaxed fine grains, directional elongated grain structure with low angle grain boundaries form inside the splats (region 1 in Fig. 8(c)) (Ref 53, 54). It is worth mentioning that some other microstructural features such as dislocation cell and twinning also form in the CS microstructure, but they are not considered here for the sake of simplicity. Additionally, the plasma atomized Ti powder used in this work had a martensitic phase structure inside Ti grains, which also is not shown in the schematic to avoid unnecessary complications. Figure 4 showed that during annealing treatment the elongated grains underwent static recrystallization (SRX) and DRX grains did grow to some extent. The schematic of the microstructure evolution during heat treatment is shown in Fig. 8 (b) and (d). One should note that the thin layer of intermetallics might form shortly upon annealing which is not considered here.

The schematic of the early stage of intermetallics formation is shown in Fig. 8(e). From a thermodynamic point of view, the chemical potential and Gibbs free energy of the intermetallic forming system determine the preferential phases. Accordingly, formation of the $\mathrm{Ni}_{3} \mathrm{Ti}$ phase is expected to be favoured and $\mathrm{Ti}_{2} \mathrm{Ni}$ and $\mathrm{NiTi}$ are, respectively, second and third. Experimental investigation of Ni$\mathrm{Ti}$ diffusion couples showed that $\mathrm{Ti}_{2} \mathrm{Ni}$ and $\mathrm{Ni}_{3} \mathrm{Ti}$ phases form at the initial step of intermetallic growth under isothermal heat treatment at 500,650 and $700{ }^{\circ} \mathrm{C}$ while the $\mathrm{NiTi}$ phase forms at the interface of these two phases thereafter. This phase formation sequence is consistent with thermodynamic based theories (Ref 56-58). Therefore, the schematic of the early stage of intermetallics formation in Fig. 8(e) assumes that $\mathrm{Ni}_{3} \mathrm{Ti}$ and $\mathrm{Ti}_{2} \mathrm{Ni}$ form on $\mathrm{Ni}$ and Ti side of the interface (Ref 32, 45, 59, 60) and NiTi phase nucleates at the interface of these two phases with some delay (Fig. 8(f)).

With the progress of $\mathrm{Ni}$ and $\mathrm{Ti}$ reactions, $\mathrm{NiTi}$ and $\mathrm{Ti}_{2} \mathrm{Ni}$ phase grow toward the center of Ti splat (Fig. 5) while $\mathrm{Ni}_{3} \mathrm{Ti}$ phase grows toward the $\mathrm{Ni}$ phase. The newly nucleated and formed grains at the Ti splat interface are always finer than the previously nucleated grains -as they experienced high temperature for a longer period of time. Figure $8(\mathrm{~g})$ shows the last stage of phase formation for the annealed sample where all the $\mathrm{Ti}$ and $\mathrm{Ti}_{2} \mathrm{Ni}$ phases are consumed and Ti splat transformed to NiTi phase with the observed gradient structure. The experimental gradient structure of NiTi for comparison is shown in Fig. 8 (h). One can conclude that the gradient grain structure is the byproduct of the deformation process and intermetallic phase nucleation and growth processes which reveals the role of the manufacturing process on the phase evolution and microstructure. 


\section{Conclusion}

CS of MMC Ni-Ti coatings and formation of intermetallics after PSHT were investigated to address the role of feedstock powder composition on deformation, composition, and microstructure characteristics of as-sprayed coatings and thereby on microstructure and intermetallic phase evolution of coatings during PSHT.

CS of physically blended Ni-Ti samples with three different feedstock powder composition using two different $\mathrm{Ni}$ powder sizes and one $\mathrm{Ti}$ powder showed that composition of feedstock powder not only influences the composition of the coatings but also it has a significant role on coating characteristics including deformation and porosities. It was shown that the coating composition has a significant role in the final phase composition of the coatings after PSHT. $\mathrm{Ti}_{2} \mathrm{Ni}$ phase was the only intermetallic found in $\mathrm{C}_{\mathrm{a}}$ coatings (Ti-rich coating), while for $\mathrm{C}_{\mathrm{v}}$ (also Ti-rich coating) and $\mathrm{C}_{\mathrm{o}}$ (almost equiatomic coating) coatings all three equilibrium intermetallics of $\mathrm{Ni}-\mathrm{Ti}$ system $\left(\mathrm{Ti}_{2} \mathrm{Ni}\right.$, $\mathrm{NiTi}$ and $\mathrm{Ni}_{3} \mathrm{Ti}$ ) coexist with the NiTi phase being dominant in $\mathrm{C}_{\mathrm{o}}$. Some porosities formed during PSHT in $\mathrm{C}_{\mathrm{v}}$ and $\mathrm{C}_{\mathrm{o}}$ coatings, which were more predominant in $\mathrm{C}_{\mathrm{v}}$ coating, with no porosity detected in $\mathrm{C}_{\mathrm{a}}$ coating. Formation of these porosities was attributed to lower quality of bonding and deformation of $\mathrm{C}_{\mathrm{v}}$ coatings in addition to Kirkendall effect inherent to Ni-Ti system which shows the role of feedstock powder composition on deformation, bonding and microstructure evolution during PSHT. The microstructure analysis showed that $\mathrm{NiTi}$ phase nucleates at $\mathrm{Ti}$ splat boundary and forms a gradient grain structure from splat boundaries toward the center of the splats. It was shown that the gradient grain structure is the by-product of grain refinement at splat boundaries and intermetallic nucleation mechanism which shows the role of the deformation and thereby manufacturing process on the microstructure and phase evolution during PSHT.

\section{References}

1. R.C. Dykhuizen and M.F. Smith, Gas Dynamic Principles of Cold Spray, J. Therm. Spray Technol., 1988, 1, p 205-212. https://doi. org/10.1361/105996398770350945

2. A. Papyrin, V. Kosarev, S. Klinkov, A. Alkimov, V. Fomin, Chapter 5 - Current status of the cold spray process, Cold Spray Technology, Elsevier, 2007, pp. 248-323, https://doi.org/10.1016/ B978-008045155-8/50005-3

3. H. Assadi, F. Gärtner, T. Stoltenhoff, and H. Kreye, Bonding Mechanism in Cold Gas Spraying, Acta Mater., 2003, 51, p 43794394. https://doi.org/10.1016/S1359-6454(03)00274-X

4. H. Assadi, T. Schmidt, H. Richter, J.-O. Kliemann, K. Binder, F. Gärtner, T. Klassen, and H. Kreye, On Parameter Selection in
Cold Spraying, J. Therm. Spray Technol., 2011, 20, p 1161-1176. https://doi.org/10.1007/s11666-011-9662-9

5. H. Assadi and F. Gärtner, Particle Compression Test: A Key Step towards Tailoring of Feedstock Powder for Cold Spraying, Coatings, 2020, 10, p 458-469. https://doi.org/10.3390/ coatings 10050458

6. W. Li, H. Assadi, F. Gaertner, and S. Yin, A Review of Advanced Composite and Nanostructured Coatings by Solid-State Cold Spraying Process, Crit. Rev. Solid. State., 2018, 44(2), p 109-156. https://doi.org/10.1080/10408436.2017.1410778

7. W. Li, C. Cao, G. Wang, F. Wang, Y. Xu, and X. Yang, 'Cold Spray +' as a New Hybrid Additive Manufacturing Technology: A Literature Review, Sci. Technol. Weld. Joi, 2019, 24(5), p 420445. https://doi.org/10.1080/13621718.2019.1603851

8. X. Xie, C. Chen, G. Ji, R. Xu, Z. Tan, Y. Xie, Z. Li, and H. Liao, A novel Approach for Fabricating a CNT/AlSi Composite with the Self-Aligned Nacre-Like Architecture by Cold Spraying, Nano Mater. Sci., 2019, 1, p 137-141. https://doi.org/10.1016/j. nanoms.2019.04.002

9. A. Sova, R. Maestracci, M. Jeandin, P. Bertrand, and I. Smurov, Kinetics of Composite Coating Formation Process in Cold Spray: Modelling and Experimental Validation, Surf. Coat. Technol., 2017, 318, p 309-314. https://doi.org/10.1016/j.surfcoat.2016.06. 084

10. R.N. Raoelison, Coeval Cold Spray Additive Manufacturing Variances and Innovative Contributions, Cold-Spray Coatings, P. Cavaliere, Ed., Springer, Berlin, 2018, p 57-94

11. X. Chu, H. Che, P. Vo, R. Chakrabarty, B. Sun, J. Song, and S. Yue, Understanding the Cold Spray Deposition Efficiencies of 316L/Fe Mixed Powders by Performing Splat Tests Onto AsPolished Coatings, Surf. Coat. Technol., 2017, 324, p 353-360. https://doi.org/10.1016/j.surfcoat.2017.05.083

12. R. Fernandez and B. Jodoin, Cold Spray Aluminum-Alumina Cermet Coatings: Effect of Alumina Content, J. Therm. Spray Technol., 2018, 27, p 603-623. https://doi.org/10.1007/s11666018-0702-6

13. M. Yandouzi, L. Ajdelsztajn, and B. Jodoin, WC-Based Composite Coatings Prepared by the Pulsed Gas Dynamic Spraying Process: Effect of the Feedstock Powders, Surf. Coat. Technol., 2008, 202, p 3866-3877. https://doi.org/10.1016/j.surfcoat.2008. 01.036

14. M. Yandouzi, H. Bu, M. Brochu, and B. Jodoin, Nanostructured Al-Based Metal Matrix Composite Coating Production by Pulsed Gas Dynamic Spraying Process, J. Therm. Spray Technol., 2012, 21, p 609-619. https://doi.org/10.1007/s11666-011-9727-9

15. R.N. Raoelison, C. Verdy, and H. Liao, Cold gas Dynamic Spray Additive Manufacturing Today: Deposit Possibilities, Technological Solutions and Viable Applications, Mater. Des., 2017, 133, p 266-287. https://doi.org/10.1016/j.matdes.2017.07.067

16. A. Bacciochini, S. Bourdon-Lafleur, C. Poupart, M. Radulescu, and B. Jodoin, Ni-Al Nanoscale Energetic Materials: Phenomena Involved During the Manufacturing of Bulk Samples by Cold Spray, J. Therm. Spray Technol., 2014, 23, p 1142-1148. https:// doi.org/10.1007/s11666-014-0078-1

17. A. Bacciochini, M. Radulescu, Y. Charron-Tousignant, J. Van Dyke, M. Nganbe, M. Yandouzi, J. Lee, and B. Jodoin, Enhanced Reactivity of Mechanically-Activated Nano-Scale Gasless Reactive Materials Consolidated by Coldspray, Surf. Coat. Technol., 2012, 206, p 4343-4348. https://doi.org/10.1016/j.surf coat.2012.02.024

18. L. Ajdelsztajn, J.M. Schoenung, B. Jodoin, and G.E. Kim, Cold Spray Deposition of Nanocrystalline Aluminum Alloys, Metall. Mater. Trans. A, 2005, 36, p 657-666. https://doi.org/10.1007/ s11661-005-0099-y

19. A. Vardelle, C. Moreau, J. Akedo, H. Ashrafizadeh, C.C. Berndt, J.O. Berghaus, M. Boulos, J. Brogan, A.C. Bourtsalas, and A. 
Dolatabadi, The 2016 Thermal Spray Roadmap, J. Therm. Spray Technol., 2016, 25, p 1376-1440. https://doi.org/10.1007/s11666016-0473-x

20. M.N. Mokgalaka, S.L. Pityana, P.A.I. Popoola, and T. Mathebula, NiTi Intermetallic Surface Coatings by Laser Metal Deposition for Improving Wear Properties of Ti-6Al-4 V Substrates, Adv. Mater. Sci. Eng., 2014, 2014, p 1. https://doi.org/10.1155/ 2014/363917

21. S. Tria, O. Elkedim, R. Hamzaoui, X. Guo, F. Bernard, N. Millot, and O. Rapaud, Deposition and Characterization of Cold Sprayed Nanocrystalline NiTi, Powder Technol., 2011, 210, p 181-188. https://doi.org/10.1016/j.powtec.2011.02.026

22. Y. Zhou, C.-J. Li, G.-J. Yang, H.-D. Wang, and G. Li, Effect of Self-Propagating High-Temperature Combustion Synthesis on the Deposition of NiTi Coating by Cold Spraying Using Mechanical Alloying Ni/Ti Powder, Intermetallics, 2010, 18, p 2154-2158. https://doi.org/10.1016/j.intermet.2010.07.006

23. J. Pattison, S. Celotto, R. Morgan, M. Bray, and W. O'Neill, Cold Gas Dynamic Manufacturing: A Non-Thermal Approach to Freeform Fabrication, Int. J. Mach. Tools Manuf, 2007, 47, p 627-634. https://doi.org/10.1016/j.ijmachtools.2006.05.001

24. C.J. Huang, X.C. Yan, W.Y. Li, W.B. Wang, C. Verdy, M.P. Planche, H.L. Liao, and G. Montavon, Post-Spray Modification of Cold-Sprayed Ni-Ti Coatings by High-Temperature Vacuum Annealing and Friction Stir Processing, Appl. Surf. Sci., 2018, 451, p 56-66. https://doi.org/10.1016/j.apsusc.2018.04.257

25. M. Bram, A. Ahmad-Khanlou, H.P. Buchkremer, and D. Stöver, Vacuum Plasma Spraying of NiTi Protection Layers, Mater. Lett., 2002, 57, p 647-651. https://doi.org/10.1016/S0167$577 \mathrm{X}(02) 00847-9$

26. T. Novoselova, S. Celotto, R. Morgan, P. Fox, and W. Oneill, Formation of TiAl intermetallics by heat treatment of coldsprayed precursor deposits, J. Alloys Compd., 2007, 436, p 69-77. https://doi.org/10.1016/j.jallcom.2006.06.101

27. H.Y. Lee, S.H. Jung, S.Y. Lee, and K.H. Ko, Alloying of ColdSprayed Al-Ni Composite Coatings by Post-Annealing, Appl. Surf. Sci., 2007, 253, p 3496-3502. https://doi.org/10.1016/j. apsusc.2006.07.053

28. S.W. Dean, J.K. Potter, R.A. Yetter, T.J. Eden, V. Champagne, and M. Trexler, Energetic Intermetallic Materials Formed by Cold Spray, Intermetallics, 2013, 43, p 121-130. https://doi.org/ 10.1016/j.intermet.2013.07.019

29. H.-T. Wang, C.-J. Li, G.-J. Yang, and C.-X. Li, Cold Spraying of $\mathrm{Fe} / \mathrm{Al}$ Powder Mixture: Coating Characteristics and Influence of Heat Treatment on the Phase Structure, Appl. Surf. Sci., 2008, 255, p 2538-2544. https://doi.org/10.1016/j.apsusc.2008.07.127

30. M. Yu and W. Li, Metal Matrix Composite Coatings by Cold Spray, Cold-Spray Coatings, P. Cavaliere, Ed., Springer, Berlin, 2018, p 297-318

31. A. Moridi, S. Hassani-Gangaraj, M. Guagliano, and M. Dao, Cold Spray Coating: Review of Material Systems and Future Perspectives, Surf. Eng., 2014, 30, p 369-395. https://doi.org/10. $1179 / 1743294414$ Y.0000000270

32. R. Nikbakht, S.H. Seyedein, S. Kheirandish, H. Assadi, and B. Jodoin, The Role of Deposition Sequence in Cold Spraying of Dissimilar Materials, Surf. Coat. Technol., 2019, 367, p 75-85. https://doi.org/10.1016/j.surfcoat.2019.03.065

33. R. Nikbakht, S.H. Seyedein, S. Kheirandish, H. Assadi, and B. Jodoin, Asymmetrical Bonding in Cold Spraying of Dissimilar Materials, Appl. Surf. Sci., 2018, 444, p 621-632. https://doi.org/ 10.1016/j.apsusc.2018.03.103

34. M. Grujicic, C.L. Zhao, W.S. DeRosset, and D. Helfritch, Adiabatic Shear Instability Based Mechanism for Particles/Substrate Bonding in the Cold-Gas Dynamic-Spray Process, Mater. Des., 2004, 25, p 681-688. https://doi.org/10.1016/j.matdes.2004.03. 008
35. Z. Arabgol, M. Villa Vidaller, H. Assadi, F. Gärtner, and T. Klassen, Influence of Thermal Properties and Temperature of Substrate on the Quality of Cold-Sprayed Deposits, Acta Mater., 2017, 127, p 287-301. https://doi.org/10.1016/j.actamat.2017.01. 040

36. J. Laeng, Synthesis of Novel Structured NiTi, School of Mechanical Engineering, $\mathrm{PhD}$ thesis, University of Western Australia, 2009

37. H. Assadi, H. Kreye, F. Gärtner, and T. Klassen, Cold SprayingA Materials Perspective, Acta Mater., 2016, 116, p 382-407. https://doi.org/10.1016/j.actamat.2016.06.034

38. G. Ali Nematollahi, E. Marzbanrad, and A.R. Aghaei, Molecular Dynamics Investigation of Mechanical Mixing in Mechanical Alloying, Mater. Sci. Eng. A, 2008, 492, p 455-459. https://doi. org/10.1016/j.msea.2008.03.049

39. R.B. Schwarz, R.R. Petrich, and C.K. Saw, The Synthesis of Amorphous Ni-Ti Alloy Powders by Mechanical Alloying, $J$. Non-Cryst. Solids, 1985, 76, p 281-302. https://doi.org/10.1016/ 0022-3093(85)90005-5

40. S. Rahmati, A. Zúñiga, B. Jodoin, and R.G.A. Veiga, Deformation of Copper particles Upon Impact: A Molecular Dynamics Study of Cold Spray, Comput. Mater. Sci., 2020, 171, p 109219. https://doi.org/10.1016/j.commatsci.2019.109219

41. R. Nikbakht and H. Assadi, Phase-Field Modelling of SelfPropagating High-Temperature Synthesis of NiAl, Acta Mater., 2012, 60, p 4041-4053. https://doi.org/10.1016/j.actamat.2012. 04.017

42. M. Elahinia, N.S. Moghaddam, M.T. Andani, A. Amerinatanzi, B.A. Bimber, and R.F. Hamilton, Fabrication of NiTi Through Additive Manufacturing: A Review, Prog. Mater Sci., 2016, 83, p 630-663. https://doi.org/10.1016/j.pmatsci.2016.08.001

43. A. Wei-Yee Tan, J.Y. Lek, W. Sun, A. Bhowmik, I. Marinescu, P.J. Buenconsejo, Z. Dong, and E. Liu, Microstructure, Mechanical and Tribological Properties of Cold Sprayed Ti6Al4 V-CoCr Composite Coatings, Compos. B. Eng., 2020, 202, p 108280. https://doi.org/10.1016/j.compositesb.2020.108280

44. I. Gutierrez-Urrutia, S. Zaefferer, and D. Raabe, Electron Channeling Contrast Imaging of Twins and Dislocations in TwinningInduced Plasticity Steels Under Controlled Diffraction Conditions in a Scanning Electron Microscope, Scripta Mater., 2009, 61, p 737-740. https://doi.org/10.1016/j.scriptamat.2009.06.018

45. M.P. Dewar, A.G. McDonald, and A.P. Gerlich, Interfacial Heating During Low-Pressure Cold-Gas Dynamic Spraying of Aluminum Coatings, J. Mater. Sci., 2012, 47, p 184-198. https:// doi.org/10.1007/s10853-011-5786-z

46. D. Goldbaum, R.R. Chromik, N. Brodusch, and R. Gauvin, Microstructure and Mechanical Properties of Ti Cold-Spray Splats Determined by Electron Channeling Contrast Imaging and Nanoindentation Mapping, Microsc. Microanal., 2015, 21, p 570581. https://doi.org/10.1017/S1431927615000240

47. G.F. Bastin and G.D. Rieck, Diffusion in the Titanium-Nickel System: II. Calculations of Chemical and Intrinsic Diffusion Coefficients, Metall. Trans., 1974, 5, p 1827-1831. https://doi. org/10.1007/BF02644147

48. C. Herzig and Y. Mishin, Grain Boundary Diffusion in Metals, Diffusion in Condensed Matter: Methods, Materials, Models, $\mathrm{P}$. Heitjans and J. Kärger, Ed., Springer, Berlin, 2005, p 337-366

49. S.F. Corbin and D. Cluff, Determining the Rate of ( $\beta$-Ti) Decay and Its Influence on the Sintering Behavior of NiTi, J. Alloys Compd., 2009, 487, p 179-186. https://doi.org/10.1016/j.jallcom. 2009.08.044

50. E. Rabkin, Y. Amouyal, and L. Klinger, Scanning Probe Microscopy Study of Grain Boundary Migration in NiAl, Acta Mater., 2004, 52, p 4953-4959. https://doi.org/10.1016/j.actamat. 2004.06.027 
51. Y. Palizdar, D. San Martin, M. Ward, R.C. Cochrane, R. Brydson, and A.J. Scott, Observation of Thermally Etched Grain Boundaries with the FIB/TEM Technique, Mater. Charact., 2013, 84, p 28-33. https://doi.org/10.1016/j.matchar.2013.07.003

52. P. Sathiyamoorthi, H. Seop Kim, High-Entropy Alloys with Heterogeneous Microstructure: Processing and Mechanical Properties, Prog. Mater Sci., 2020, In press, https://doi.org/10. 1016/j.pmatsci.2020.100709

53. X.-T. Luo, C.-X. Li, F.-L. Shang, G.-J. Yang, Y.-Y. Wang, and C.-J. Li, High Velocity Impact Induced Microstructure Evolution During Deposition of Cold Spray Coatings: A Review, Surf. Coat. Technol., 2014, 254, p 11-20. https://doi.org/10.1016/j. surfcoat.2014.06.006

54. Y. Zou, W. Qin, E. Irissou, J.-G. Legoux, S. Yue, and J.A. Szpunar, Dynamic Recrystallization in the Particle/Particle Interfacial Region of Cold-Sprayed Nickel Coating: Electron Backscatter Diffraction Characterization, Scripta Mater., 2009, 61, p 899-902. https://doi.org/10.1016/j.scriptamat.2009.07.020

55. R. Nikhbakht, M. Saadati, M. Jahazi, H. Assadi, and B. Jodoin, EBSD Analysis Enhancement of Cold Sprayed Composite Materials: Sample Preparation, Annealing, and Scan Optimization, Microscopical Society Symposium of Canada, Université de Sherbrooke, Québec, Canada, 2020
56. L. Hu, Y. Xue, and F. Shi, Intermetallic Formation and Mechanical Properties of Ni-Ti Diffusion Couples, Mater. Des., 2017, 130, p 175-182. https://doi.org/10.1016/j.matdes.2017.05. 055

57. G. Chen, K.-D. Liss, and P. Cao, An In Situ Study of NiTi Powder Sintering Using Neutron Diffraction, Metals, 2015, 5, p 530. https://doi.org/10.3390/met5020530

58. Y. Zhou, Q. Wang, D.L. Sun, and X.L. Han, Co-effect of Heat and Direct Current on Growth of Intermetallic Layers at the Interface of Ti-Ni Diffusion Couples, J. Alloys Compd., 2011, 509, p 1201-1205. https://doi.org/10.1016/j.jallcom.2010.09.182

59. C. Lee and J. Kim, Microstructure of Kinetic Spray Coatings: A Review, J. Therm. Spray Technol., 2015, 24, p 592-610. https:// doi.org/10.1007/s11666-015-0223-5

60. J.Y. Lek, A. Bhowmik, A.W.-Y. Tan, W. Sun, X. Song, W. Zhai, P.J. Buenconsejo, F. Li, E. Liu, Y.M. Lam, and C.B. Boothroyd, Understanding the Microstructural Evolution of Cold Sprayed Ti6Al-4V Coatings on Ti-6Al-4V Substrates, Appl. Surf. Sci., 2018, 459, p 492-504. https://doi.org/10.1016/j.apsusc.2018.07.175

Publisher's Note Springer Nature remains neutral with regard to jurisdictional claims in published maps and institutional affiliations. 